\title{
The working of a labour market model with potential entry
}

Citation for published version (APA):

Maks, J. A. H., Zwick, T., Haan, M., Bunte, F. H. J., \& Muysken, J. (1995). The working of a labour market model with potential entry. METEOR, Maastricht University School of Business and Economics. METEOR Research Memorandum No. 010 https://doi.org/10.26481/umamet.1995010

Document status and date:

Published: 01/01/1995

DOI:

10.26481/umamet.1995010

Document Version:

Publisher's PDF, also known as Version of record

\section{Please check the document version of this publication:}

- A submitted manuscript is the version of the article upon submission and before peer-review. There can be important differences between the submitted version and the official published version of record.

People interested in the research are advised to contact the author for the final version of the publication, or visit the DOI to the publisher's website.

- The final author version and the galley proof are versions of the publication after peer review.

- The final published version features the final layout of the paper including the volume, issue and page numbers.

Link to publication

\footnotetext{
General rights rights.

- You may freely distribute the URL identifying the publication in the public portal. please follow below link for the End User Agreement:

www.umlib.nl/taverne-license

Take down policy

If you believe that this document breaches copyright please contact us at:

repository@maastrichtuniversity.nl

providing details and we will investigate your claim.
}

Copyright and moral rights for the publications made accessible in the public portal are retained by the authors and/or other copyright owners and it is a condition of accessing publications that users recognise and abide by the legal requirements associated with these

- Users may download and print one copy of any publication from the public portal for the purpose of private study or research.

- You may not further distribute the material or use it for any profit-making activity or commercial gain

If the publication is distributed under the terms of Article $25 \mathrm{fa}$ of the Dutch Copyright Act, indicated by the "Taverne" license above, 


\title{
The Working of a Labour Market Model with Potential Entry
}

\author{
Thomas Zwick
}

Frank Bunte, Marco Haan, Hans Maks, Joan Muysken

\section{Abstract}

In this paper the effects of different institutional scenarios on rent creation and rent distribution in a labour market are studied. Rent is generated by sinking costs in human capital investment and this rent is distributed between firms and workers by the wage set. In the bench-mark scenario the social planner can determine both, the investment in human capital and the wage, such that the rent created is maximal and given entirely to the firm. In the so-called monopolistic worker scenario the worker can determine investment and wage, while in the so-called monopsonistic firm scenario the firm determines the wage and the worker decides over investment. These scenarios are contrasted by the insider-outsider scenario, where the monopolistic incumbent may be outperformed by an entrant.

It is shown that the incumbent will always find it advantageous to preempt the outsider in this setting, even if this leads to distortions in her behaviour. While the monopolistic worker and insider have an incentive to invest (almost) efficiently, because they can skim most of the rent created. This is not the case in the monopsonistic firm scenario, where the firm can appropriate most of the rent. There are comparative statics performed in order to show the impact of the different parameters on the results. 


\section{Introduction}

The objective of this paper is to show the consequences of introducing human capital formation and uncertainty into an insider-outsider labour market model. We are interested how strongly the outcomes deviate from the results, we would expect from contestability theory where these features are not assumed ${ }^{1}$. The main objective is to analyse the dynamic and static performance of the scenario where there is an incumbent worker and a potential entrant. With dynamic efficiency the increase in human capital is meant and with static efficiency the distribution of the rent generated by the investment in human capital ${ }^{2}$. In other words dynamic efficiency concerns the rent generated by human capital formation, while static efficiency is rent distribution.

The performance of the insider-outsider scenario is contrasted by the benchmark-scenarios of a social planner, a monopolistic worker where the worker decides over investment in human capital and wage setting herself and a monopsonistic firm where the representative worker is a wage-taker.

There is a representative worker and a representative firm. The firm has an explicit profit function on a per-worker basis. Increases in human capital by the worker raise the (expected) marginal value product of labour ${ }^{3}$.

Higher human capital can be achieved through investing in schooling in the previous period. The production of human capital through investment in schooling is certain, but the productivity of the newly acquired human capital is unknown when investing in human capital. It is assumed that the agents just maximize the problem with a two-period time horizon.

In chapter 2, we introduce the fundamental structure of the model by stating the profit function of the firm, the utility function of the worker and the "production technology" of human capital. In chapter 3, the concrete solutions of the benchmark scenarios social planner, monopsonistic firm and monopolistic worker are derived. In chapter 4, the insider-outsider scenario is introduced. Chapter 5 finally provides a

\footnotetext{
${ }^{1}$ Compare e.g. Baumol et al, 1988, pp. 347 - 360.

${ }^{2}$ Compare Witteloostuijn (1990) p. 213.

${ }^{3}$ Compare e.g. Becker (1983), p. 17.
} 
summary of the results.

\section{Fundamental Structure}

\subsection{Profit Function of the Firm}

The marginal productivity of the worker is assumed to be the square root of the accumulated human capital. As other inputs are not taken into account, the production function can be therefore specified as below, where $\mathrm{c}$ is the new human capital created in the period under consideration T, $c_{\mathrm{T}}{ }^{k} \equiv \mathrm{c}^{\mathrm{b}}$ and $\mathrm{x}$ is the weighted sum of the human capital accumulated in the previous periods, $\Sigma_{\mathrm{t}=0}^{\mathrm{T}-1} \mathrm{c}_{\mathrm{t}}{ }^{\mathrm{h}} \equiv \mathrm{x}^{\mathrm{k}}$. The effect of the newly created human capital is a-priori uncertain and therefore enters with a term for expectation (expected values are indicated by "E").

$$
\operatorname{Ef}(x, c)=x^{k}+E c^{k}
$$

The firm has to pay a bonus w for the newly created human capital $c$ that is determined in the current period, while the wage v for the exogenous "old" human capital $\mathrm{x}$ is given (determined "by history").

The return of human capital to the firm is modelled with decreasing returns to scale and has to be multiplied by the exogeneous market price $\mathrm{p}$ in order to get total revenue of one worker. The costs for additional labour productivity increase linearly, however.

It is assumed that the additional productivity of the newly acquired human capital is dependent on a stochastic event. The stochast has the low realization $(1-\varepsilon)$ with probability 0.5 and with the same probability the high realization $(1+\varepsilon)$ occurs. It is assumed that the parameter $\varepsilon$ lies in the domain of $[0,0.25]$. This constraint on the uncertainty of investment in human capital does not change the qualitative results and makes the line of argument at several points easier. We can write the profit function of the firm in the good and the bad state then as follows:

$$
\begin{aligned}
\pi^{\mathrm{low}}(\mathrm{c}, \mathrm{W}) & =\mathrm{px}^{\mathrm{k}}+(1-\varepsilon) p c^{\mathrm{k}}-\mathrm{vx}-\mathrm{wc} \\
\pi^{\mathrm{high}}(\mathrm{c}, \mathrm{W}) & =\mathrm{px}^{\mathrm{k}}+(1+\varepsilon) p c^{\text {k }}-\mathrm{vx}-\mathrm{wc}
\end{aligned}
$$

Due to the simple specification of the stochast, expected profit of the firm can then be written as:

$$
E \boldsymbol{\pi}(c, W)=p\left(X^{k}+c^{k}\right)-V X-W c
$$


The reservation level of profits for the firm is $p \mathrm{x}^{k}-\mathrm{vx}$, the level of profit achieved with the "old" human capital. Therefore, the bonus wc for the worker cannot be higher than the additional revenue gained by the firm. If there is a steady development in human capital due to education, the reservation level of profit of the firm also increases over time.

It is assumed that if the profit the incumbent grants the firm is the same as the profit the potential entrant is able to offer, the firm decides to keep the incumbent.

\subsection{Surplus Function of the Worker}

The worker maximizes his utility. We assume that utility in this case is equal to the monetary surplus he can realize in a certain period minus the investment i necessary to create new human capital c. The worker offers inelastically one unit of labour, but can influence his productivity by investing in human capital.

The surplus function of the worker can be written like this:

$$
s(i, w)=v x+w c-(1+r) i
$$

The worker earns the basic wage vx plus a bonus w for the newly acquired human capital $c$ and he has to subtract the effort $i$ for acquiring $c$ in the last period, therefore $i$ has to be multiplied by the exogeneous interest-rate $(1+r)$. We assume that the reservation surplus level of the worker is vx. If the wage payment is lower then the worker decides to quit his job.

\section{3 "Production" of Human Capital}

We assume that with investment $i$ in education in one period, there can a certain amount of human capital c be gained in the following period with decreasing returns to scale. The given a is a parameter that determines the efficiency of producing new human capital.

The production function of human capital is defined as follows:

$$
c(i)=a i^{4}\left[\text { or } i(c)=(c / a)^{2}\right]
$$

\section{Benchmark Results}




\subsection{The Social Planner}

In the social planner scenario, we look for a solution of the structure given in chapter 2 that is characterized by two features. On the one hand, the rent generated by investment in human capital should by maximal (we call that dynamic efficiency, because it is related to the building of human capital over time). On the other hand the share on the rent generated by new human capital given to the firm is maximal (static efficiency), i.e. the worker just earns a bonus that covers his expenses for investing in human capital in the previous period. This set-up is chosen, because we are looking at the performance of the contestable labour market and contestability theory suggests that there is no surplus earned by the incumbent worker, while she has an incentive to invest efficiently in human captial. We could motivate this set-up by assuming that the firm is publicly owned and that the profits of the firm are therefore enhancing social welfare, while the surplus is kept private by the worker.

We will call from now on the difference between the social welfare achieved and the reservation level of firm's profit $\mathrm{px}^{\mathrm{k}}-\mathrm{vx}$ "social surplus".

The approach taken therefore is that the welfare function comprises just the (expected) profits of the firm $\pi$ (2.3). The larger the share of the rent the firm gets and the larger the rent generated itself, the larger the social welfare in our setting.

Therefore the expected social welfare function sw is defined as:

$$
\operatorname{Esw}\left(c^{\mathrm{sp}}\right)=p \mathrm{x}^{\mathrm{k}}+\mathrm{pc}_{\mathrm{sp}}{ }^{\mathrm{k}}-\mathrm{vX}-\mathrm{W}^{\mathrm{sp}} \mathrm{c}^{\mathrm{sp}}
$$

In this case, we derive the maximal social welfare optimizing (3.1) under the constraint the worker enjoys just his reservation profit vx. So we can make sure that the rent is maximized and the firm gets the entire rent.

The objective function of the social planner reads then as:

$$
\max \text { Esw s.t. } \mathrm{s}^{\mathrm{sp}}=\mathrm{VX}+\mathrm{w}^{\mathrm{sp}} \mathrm{c}^{\mathrm{sp}}-(1+\mathrm{r}) \mathrm{s}^{\mathrm{sp}}=\mathrm{vX}
$$

The resulting efficient new human capital and bonus demand are:

$$
\mathrm{c}^{\mathrm{sp}}=\left(\frac{\mathrm{p}}{2 \mathrm{w}}\right)^{2}
$$




$$
\mathrm{w}^{\mathrm{sp}}=\left(\frac{(1+\mathrm{r}) \mathrm{p}^{2}}{16 \mathrm{a}^{2}}\right)^{\frac{1}{3}}
$$

If we substitute (3.4) into (3.3), we get the optimal investment in human capital (dynamic efficiency):

$$
c^{s p}=\left(\frac{a^{2} p}{4(1+r)}\right)^{\frac{2}{3}}
$$

The expected level of social welfare reads then as:

$$
E s w^{s p}=p x^{\frac{1}{2}}-v x+\left(\frac{3}{4}\right)\left(\frac{a^{2} p^{4}}{4(1+r)}\right)^{\frac{1}{3}}=E \pi^{s p}
$$

Notice that the social surplus is here the third expression on the right hand side of equation (3.5). The surplus of the worker is of course equal to the reservation level vx. In order to facilitate the notation, we will write from now on:

$$
\alpha \equiv\left(\frac{\mathrm{a}^{2} \mathrm{p}^{4}}{4(1+\mathrm{r})}\right)^{\frac{1}{3}}
$$

Notice that $\alpha$ is the square root of dynamic efficiency.

\subsection{The Decision of the Monopolistic Worker}

The monopolist worker determines both, investment in human capital and the bonus charge. There are two opportunities: She could ask for a $c^{\mathrm{m}}-\mathrm{w}^{\mathrm{m}}$ combination (superscript "m" stands for monopolistic worker) such that her certain surplus (2.4) is maximal under the constraint that her employer earns the reservation profit $\mathrm{px}^{\mathrm{k}}-\mathrm{vx}$ if the stochast turns out to be low. The other possibility is that the monopolistic worker maximizes $\mathrm{s}^{\mathrm{m}}$ under the constraint that her employer earns the reservation profit if the stochast is high and is fired if the stochast is low (with chance 0.5). We have chosen the set-up, as 
will be shown below, such that the first version is preferred by a risk-neutral worker in order to facilitate the argumentation in the insider-outsider scenario. Therefore we just calculate explicitly the strategy without risk:

$$
\pi_{\text {low }}^{\mathrm{m}}=\mathrm{px}^{\mathrm{h}}-\mathrm{vX}+(1-\varepsilon) \mathrm{pc}_{\mathrm{m}}{ }^{\mathrm{h}}-\mathrm{w}^{\mathrm{m}} \mathrm{C}^{\mathrm{m}}=\mathrm{px}^{\mathrm{h}}-\mathrm{vX}
$$

The bonus charge is a function of $\mathrm{c}^{\mathrm{m}}$ and can be derived from (3.7):

$$
\mathrm{w}^{\mathrm{m}}\left(\mathrm{c}^{\mathrm{m}}\right)=(1-\varepsilon) \mathrm{pc}_{\mathrm{m}}^{-\mathrm{k}}
$$

The objective function of the monopolistic worker reads then as:

$$
S^{m}\left(c^{m}\right)=v X+(1-\varepsilon) p c_{m}{ }^{k}-(1+r) \frac{\mathbf{c}_{\mathbf{m}}^{2}}{\mathbf{a}^{2}}
$$

The (certain) optimal level of additional human capital of the monopolist can be found by taking the first order derivative of (3.9) with respect to $\mathrm{c}^{\mathrm{m}}$ :

$$
\mathrm{c}^{\mathrm{m}}=\left(\frac{\mathrm{a}^{2}(1-\epsilon) \mathrm{p}}{4(1+\mathrm{r})}\right)^{\frac{2}{3}}=(1-\epsilon)^{\frac{2}{3}} \mathrm{c}^{\mathrm{sp}}
$$

Notice that the monopolist invests too little in comparison to the social planner scenario. The higher $\boldsymbol{\varepsilon}$ (and thus uncertainty) the larger the gap between both bench-marks. Substituting the surplus-maximizing creation of new human capital into the wage function (3.8), we derive:

$$
\mathrm{w}^{\mathrm{m}}=\left(\frac{4(1-\epsilon)^{2}(1+\mathrm{r}) \mathrm{p}^{2}}{\mathrm{a}^{2}}\right)^{\frac{1}{3}}=4(1-\epsilon)^{\frac{2}{3}} \mathrm{w}^{\mathrm{sp}}
$$

Thus the wage demand of the monopolist is larger than that of the worker in the social planner scenario. The wage demand of the monopolist is negatively correlated with uncertainty. The certain surplus the monopsonist enjoys is then:

$$
S^{m}=v X+\left(\frac{3}{4}\right)(1-\varepsilon)^{\frac{4}{3}} \alpha
$$

The surplus of the monopolist is of course also negatively correlated with uncertainty and 
for all parameter constellations larger than the reservation surplus vx.

The surplus of the second strategy with uncertainty would read as the equation below, if the outside option (or the wage level by another employer) is vx:

$$
E S^{m}=v X+\left(\frac{3}{8}\right)(1+\varepsilon)^{\frac{4}{3}} \alpha
$$

As we are interested in the bench-mark scenarios in situations where the worker stays in the labour market with certainty, we have to make sure that equation (3.12) is larger than (3.13) for the risk neutral worker. Therefore $\boldsymbol{\varepsilon}$ should be smaller than the expression below, what is always the case $e^{4}$.

$$
\epsilon<\frac{1-\left(\frac{1}{2}\right)^{\frac{3}{4}}}{1+\left(\frac{1}{2}\right)^{\frac{3}{4}}}
$$

The expected profit of the firm and the expected social welfare with $\mathrm{w}^{\mathrm{m}}$ is in this scenario:

$$
\mathrm{E} \pi^{\mathrm{m}}=\mathrm{px}^{\frac{1}{2}}-\mathrm{vx}+(1-\epsilon)^{\frac{1}{3}} \epsilon \alpha=\mathrm{Esw}^{\mathrm{m}}
$$

Notice that $E \pi^{\mathrm{m}}<E \pi^{\mathrm{sp}}$ irrespectively of $\boldsymbol{\varepsilon}$, because $\boldsymbol{\varepsilon}$ lies in $[0,0.25]$, compare equation (3.5). As the monopolistic worker has to take the reservation profit constraint into consideration, the profit of the firm increases with uncertainty. The possibility of the monopolist to skim the entire surplus is thus bounded by uncertainty and she has to let the firm enjoy a part of it. The actual values of firm's profit for the different realizations of the stochast are:

\footnotetext{
${ }^{4}$ This figure is roughly 0.254 . That is one of the reasons to confine the domain fo $\varepsilon$. Alternatively, there could be also risk-aversion of the worker assumed or a lower outside option of the monopolistic worker. This would increase the range of $\varepsilon$.
} 


$$
\begin{gathered}
\pi_{\text {high }}^{\mathrm{m}}=\mathrm{px}^{\frac{1}{2}}-\mathrm{vx}+2(1-\epsilon)^{\frac{1}{3}} \epsilon \alpha \\
\pi_{\text {low }}^{\mathrm{m}}=\mathrm{px}^{\frac{1}{2}}-\mathrm{vx}
\end{gathered}
$$

In this scenario, the monopolistic worker behaves only then dynamically efficient, if there is no uncertainty. As she is able to skim most of the social surplus however, this scenario is staticly inefficient and the expected social welfare is lower for all parameter constellations than in the social planner scenario, but increasing in $\boldsymbol{\varepsilon}$ (compare (3.14)).

\subsection{The Firm as Monopsonist}

Another bench-mark scenario is given by the assumption that the worker is a wage taker and can just adapt his investment i. As the firm can set now the wage, it can reduce its risk by proposing a state-contingent wage contract. The firm maximizes its profit by setting the appropriate state-contingent wage levels, taking into account that the worker will invest such that his surplus is maximized.

$$
\max \pi \text { s.t. c(w) }
$$

We derive the "supply function" of human capital by the worker that is dependent on the wage offered by differentiating the surplus function (2.4) with respect to c:

$$
c^{w t}(w)=\frac{a^{2} w}{2(1+r)}
$$

The superscript "wt" stands for wage taker.

The firm determines the optimal bonus by maximizing the profits in the different realisations of the stochast (2.1) or (2.2) taking the reaction curve of the worker (3.17) into account:

$$
\pi_{\text {high }}^{\mathrm{wt}}(\mathrm{w})=\mathrm{px}^{\frac{1}{2}}+\frac{(1+\epsilon) \mathrm{apw}^{\frac{1}{2}}}{2^{\frac{1}{2}}(1+\mathrm{r})^{\frac{1}{2}}}-\mathrm{vx}-\frac{\mathrm{a}^{2} \mathrm{w}^{2}}{2(1+\mathrm{r})}
$$




$$
\pi_{\text {low }}^{\mathrm{wt}}(\mathrm{w})=\mathrm{px}^{\frac{1}{2}}+\frac{(1-\epsilon) a p w^{\frac{1}{2}}}{2^{\frac{1}{2}}(1+\mathrm{r})^{\frac{1}{2}}}-\mathrm{vx}-\frac{\mathrm{a}^{2} \mathrm{w}^{2}}{2(1+\mathrm{r})}
$$

In order to maximize the objective function of the firm, we have to take the first order derivative of (3.18) and (3.19) respectively with respect to $\mathrm{w}$. The resulting bonus level is in both states of the nature:

$$
\begin{gathered}
w_{\text {high }}^{\mathrm{wt}}=\left(\frac{(1+\varepsilon)^{2}(1+r) p^{2}}{8 a^{2}}\right)^{\frac{1}{3}} \\
\mathrm{w}_{\text {low }}^{\mathrm{wt}}=\left(\frac{(1-\varepsilon)^{2}(1+r) p^{2}}{8 a^{2}}\right)^{\frac{1}{3}} \\
\text { EW }^{\mathrm{wt}}=\left(\frac{1}{2}\left[(1+\varepsilon)^{\frac{2}{3}}+(1-\varepsilon)^{\frac{2}{3}}\right]\right)\left(\frac{(1+r) p^{2}}{8 a^{2}}\right)^{\frac{1}{3}} \approx\left(\frac{1}{2}\right)^{\frac{2}{3}} \mathrm{~W}^{\mathrm{sp}}
\end{gathered}
$$

The expected bonus induces the worker - substituting the expected value of $\mathrm{w}$ (3.22) into (3.17) - to an increase in human capital of the following amount, independent on the resulting stochast, because the worker has to decide beforehand on the investment:

$$
c^{w t}=\left(\frac{a^{2} p}{8(1+r)}\right)^{\frac{2}{3}}=\left(\frac{1}{2}\right)^{\frac{2}{3}} c^{s p}
$$

Thus the creation of new human capital is too small (dynamically inefficient), if we compare it with the social planner scenario.

The expected profit of the firm and the social welfare is about, assuming for simplicity that the first bracket in (3.22) equals 1 : 


$$
\mathrm{E} \pi^{\mathrm{wt}} \approx \mathrm{px} \mathrm{x}^{\frac{1}{2}}-\mathrm{vx}+\frac{3}{8}\left(\frac{\mathrm{a}^{2} \mathrm{p}^{4}}{(1+\mathrm{r})}\right)^{\frac{1}{3}}=\frac{3}{2^{\frac{7}{3}}} \pi^{\mathrm{sp}} \approx \mathrm{Esw}^{\mathrm{wt}}
$$

This expression is derived by substituting (3.23) and (3.21) into (2.3). Therefore the profit the firm enjoys when the worker is a wage taker is higher than in the monopolistic worker scenario (compare (3.25) with (3.15) and (3.24) with (3.16)) In addition to that, the firm is able to shift part of the risk to the worker by paying state-dependent bonuses. The worker can acquire just $1 / 7$ of the social surplus and has no large incentive to invest into human capital, while the firm -being able to determine the wage levelgets by far the larger share. Taken together, welfare is unambigously higher than in the monopsonistic scenario, but clearly lower than in the social planner scenario.

The expected surplus of the wage taking worker is in this scenario:

$$
\mathrm{Es}^{\mathrm{wt}} \approx \mathrm{vx}+\frac{1}{16}\left(\frac{\mathrm{a}^{2} \mathrm{p}^{4}}{(1+\mathrm{r})}\right)^{\frac{1}{3}}=\mathrm{vx}+\frac{1}{4^{\frac{5}{3}}} \alpha
$$

\section{The Insider-Outsider Scenario}

\subsection{The Set-up}

It is assumed that the incumbent works for a firm in the primary labour market, while the potential entrant works in the secondary labour market and is seeking for work in the primary labour market. This is oriented at the so-called "Dual Labour Market Theory"6. If the entrant outperforms the incumbent, she is replaced by her rival and forced to accept a job at the secondary labour market. We assume therefore that no

${ }^{5}$ The last term in $(3.25)$ is approximately $[0.43,0.76] \alpha$ within the range of $\varepsilon$, while the last expression in (3.5) gives accordingly $[0,0.23] \alpha$.

${ }^{6}$ See e.g. Lindbeck/Snower (1988) p. $246 f$. 
actual competition takes place after entrance ("hit and stay entry") "total", i.e. the entrant takes over the entire market (in this case the job in the primary labour market). Consequently, no reaction of the incumbent on entrance is possible, taking the fact into account that a dismissed worker hardly ever is able to win back his former position. Both rivals compete in the creation of new human capital and the bonus demand.

It is assumed that human capital has a positive influence on productivity just in the primary labour market, while it is not important in the secondary labour market. The gained human capital is therefore specific for the firm in the primary labour market. ${ }^{9}$ The stock of human capital by both rivals is assumed to be of the same value for the firm, it is therefore possible to acquire the needed human capital by (publicly accesible) schooling and not only by training on the job. The productivity of the worker in the secondary labour market is not dependent on human capital. Consequently, the outsider or the fired incumbent can't earn back his/her investment in the secondary labour market. Thus there are - as is generally observed ${ }^{10}$ - sunk costs (or exit costs) attached to investment in human capital introduced in the insider-outsider scenario.

It is assumed that the firm gives the incumbent the slight preference to keep her, if both rivals offer exactly the same profit to it. The (monetary) surplus function s of the incumbent is defined as:

$$
S\left(c^{\mathrm{i}}, W^{\mathrm{i}}\right)=\begin{aligned}
& \operatorname{vX}+\mathrm{W}^{\mathrm{i}} c^{\mathrm{i}}-(1+r) \mathrm{i}^{\mathrm{i}}, \text { if } \pi^{\mathrm{i}} \geq \pi^{\mathrm{e}} \\
& \mathrm{u}-(1+\mathrm{r}) \mathrm{i}^{\mathrm{i}}, \text { if } \pi^{\mathrm{i}}<\pi^{\mathrm{e}}
\end{aligned}
$$

If the incumbent offers the firm a higher or equal profit than the potential entrant, she earns a wage bill split into two parts, vx and wc. If the entrant can outperform the insider, she is fired and just earns $u$, the wage level at the secondary labour market and has to substract additionally the investment in human capital of the last period multiplied by the interest rate $(1+r)$.

\footnotetext{
${ }^{7}$ See e.g. Schwartz (1986) p. 42.

${ }^{8}$ Compare Shepherd (1984), p.537.

${ }^{9}$ Compare Robert Hart (1984), p. 35.

${ }^{10}$ See Witteloostuijn (1990) p. 217.
} 
The surplus function of the entrant looks analogously like this:

$$
S^{e}\left(c^{e}, w^{e}\right)=\begin{aligned}
& v x+w^{e} c^{e}-(1+r) i^{e}, \text { if } \pi^{i} \leq \pi^{e} \\
& u-(1+r) i^{e} \text {, if } \pi^{i}>\pi^{e}
\end{aligned}
$$

When investing, the worker just takes the following period -where the education results in a higher productivity - into consideration. In order to introduce credible commitments into the game ${ }^{11}$, it is assumed that the incumbent invests before the potential entrant does. The entrant then decides how much to invest himself knowing the commitment of his rival. In the following period, both agents decide simultaneously about the bonus demand knowing the investment of the other one, but not knowing the realization of the stochast. The game and the time horizon of the players is two periods.

This is the basic structure of the game ${ }^{12}$.

\section{Period Stage}

11 investment decision $\mathrm{i}^{\mathrm{i}}$ of the incumbent

2 investment decision $\mathrm{i}^{\mathrm{e}}$ of the potential entrant

23 new human capital $\mathrm{c}$ is gained by both rivals as a consequence of $\mathrm{i}$

4 bonus is set by the rivals for known $\mathrm{c}$

5 realization of stochast $(1+\varepsilon)$ or $(1-\varepsilon)$ in profit function of the firm

6 firm decides: incumbent is kept, if $\pi^{\mathrm{i}}(\mathrm{w}, c) \geq \pi^{\mathrm{e}}(\mathrm{w}, \mathrm{c})$.

entrant is taken, if $\pi^{\mathrm{i}}<\pi^{e}$

In order to solve the model, we concentrate on Nash-equilibria and therefore for scenarios where the reactions of the rivals are alternately consistent. We will compare therefore the surpluses resulting from the different scenarios and choose the scenario that grants the incumbent the highest surplus while the potential entrant does not have an incentive to change his decision either.

After investment in stage 1 and 2, the incumbent has two options for her bonus

\footnotetext{
${ }^{11}$ Tirole (1988) observes that sunk costs always have a commitment value, see p. 314.

12 The game is modelled like a Stackelberg-game where the incumbent enjoys a first-mover advantage, confer e.g. the model presented in Tirole (1988), p. $315 f$.
} 
setting. Either she can accomodate or preempt. The threat of preemption is a priori only then credible if it grants the incumbent a posteriori (after the potential entrant has indeed invested) a higher surplus by setting a wage demand that allows for entry. If the incumbent can credibly threat the potential entrant with preemption, then the outsider will not invest at all and prefer to stay in the secondary labour market. If preemption is not credible, the potential entrant will invest in human capital and try to outperform the incumbent as long as the expected surplus is higher than the wage level in the secondary labour market u.

\subsection{The Structure of Chances}

Due to the discrete set-up of the stochast and the fact that the stochasts of the rivals are not correlated, the probability of the outsider to outperform the incumbent $\Omega$ can take 4 discrete values: 0, 0.25, 0.5 and 0.75 . Probability one is not possible, because the insider can always imitate the behaviour of the outsider and due to the marginal advantage the firm grants the incumbent, the maximal chance of the outsider is 0.75 . On every probability there is a certain investment-bonus combination of the potential entrant attached that can be derived from (4.4) and (4.5). The investment-bonus combination also gives the expected profits (4.6) and the profits enjoyed by the firm in the different realizations of $\varepsilon(4.7)$ and (4.8) as a function of $\Omega$. Notice that the expected surplus of the outsider increases with $\Omega$, i.e. the potential entrant has always an incentive to commit himself as high as possible (or choose the scenario with the highest $\Omega$.

The following table gives an overview of the possible realizations of $\pi$ :

\begin{tabular}{|c|c|c||}
\hline \hline Table 1 & $\pi_{\text {low }}^{\mathrm{i}}$ & $\pi_{\text {high }}^{\mathrm{i}}$ \\
\hline$\pi_{\text {low }}^{\mathrm{e}}$ & $1 / 4$ & $1 / 4$ \\
\hline$\pi_{\text {high }}^{\mathrm{e}}$ & $1 / 4$ & $1 / 4$ \\
\hline
\end{tabular}

The stochast realizes itself therefore independent of the worker and all profit combinations are observed with chance $1 / 4$. The probability of the potential entrant to outperform his rival is therefore dependent on the relation between the profit he offers in both 
realizations of the stochast to the profit the incumbent offers. The incumbent maximizes her expected surplus taking into consideration that her commitment and the bonus demand in stage 4 influences the relation between the profits and thus $\Omega$.

The entrant can outperform the incumbent with probability 0.75 , if the profit of the firm the incumbent offers in the good state is only higher than the profit the firm enjoys from the outsider if the bad state realizes itself. Then the incumbent only stays in the primary labour market if "her" stochast is high while the stochast of the outsider is low. In all other combinations the incumbent is outperformed by her rival.

The probability $\Omega$ is 0.5 if the incumbent outperforms the potential entrant only if her stochast is high and is outperformed if her stochast is low regardless the realization of the rival's stochast $\left(\pi_{\text {high }}^{\mathrm{i}} \geq \pi_{\text {high }}^{\mathrm{e}}>\pi_{\text {low }}^{\mathrm{e}}>\pi_{\text {low }}^{\mathrm{i}}\right)$.

The probability is then 0.25 if the outsider just outperforms the insider if his stochast is high and the stochast of the rival is low. The relation between the profits of the rivals is then: $\pi_{\text {high }}^{\mathrm{i}}>\pi_{\text {high }}^{\mathrm{e}}>\pi_{\text {low }}^{\mathrm{i}} \geq \pi_{\text {low }}^{\mathrm{e}}$.

The parameter $\Omega$ is finally zero, if the incumbent outperforms the entrant in both realizations of the stochast, therefore if $\pi_{\text {low }}^{\mathrm{i}} \geq \pi_{\text {high }}^{\mathrm{e}}$.

Summing up, we can see the following correlations between the profit the firm in the primary labour market enjoys and the chance the potential entrant has to get the job in the primary labour market. ${ }^{13}$ As the incumbent maximizes her utility, she transforms all greater than or equal-signs to equalities:

\begin{tabular}{|c|c||}
\hline$\Omega$ & profits offered \\
\hline 0.75 & $\pi_{\text {high }}^{\mathrm{i}}=\pi_{\text {low }}^{\mathrm{e}}$ \\
\hline 0.5 & $\pi_{\text {high }}^{\mathrm{i}}=\pi_{\text {high }}^{\mathrm{e}}$ \\
\hline 0.25 & $\pi_{\text {low }}^{\mathrm{i}}=\pi_{\text {low }}^{\mathrm{e}}$ \\
\hline 0 & $\pi_{\text {low }}^{\mathrm{i}}=\pi_{\text {high }}^{\mathrm{e}}$ \\
\hline
\end{tabular}

Tabel 2

\footnotetext{
13 The correlation between the profits are given under the assumption that the investment of the insider is larger than the investment of the outsider. It will be shown later that this always the case in equilibrium.
} 


\subsection{The Behaviour of the Outsider}

The potential entrant is assumed to maximize his expected surplus. He knows that the firm maximizes its profits and has a (falling) demand function for human capital as a function of the bonus charged for it. The optimal offer of the potential entrant lies therefore at the point where his surplus-maximal increasing supply function of newly acquired human capital crosses the demand function of the firm.

The wage demand of the potential entrant can be calculated as a function of additional human capital by maximizing the expected surplus. This is done by weighting the surplus achieved in the secondary and primary labour market from (4.2) with the chance $\Omega$ that the potential entrant can outperform the incumbent and achieve the job in the primary labour market:

$$
\operatorname{Es}^{e}\left(W^{e}, c^{e}\right)=\Omega\left(v X+W^{e} c^{e}-(1+r) i^{e}\right)+(1-\Omega)\left(u-(1+r) i^{e}\right)
$$

The outsider takes the first order derivative of (4.1) with respect to $c^{e}$ in order to maximize his utility:

$$
c^{e}\left(w^{e}\right)=\frac{w^{e} a^{2} \Omega}{2(1+r)}
$$

Notice that this is the "supply function" of human capital by the worker in chapter 3.3 where the firm acts as a monopsonist (compare equation (3.17)), taking the chance $\Omega$ into account that he gets the job in the primary labour market.

The demand function of the firm can be derived by maximizing the expected profit function of the firm (2.4) with respect to c:

$$
c(w)=\left(\frac{p}{2 w}\right)^{2}
$$

If the "reaction functions" (4.4) and (4.5) are set equal, we get the equilibrium solution for the newly acquired human capital of the outsider $c^{\mathrm{e}}$ :

$$
c^{e}=\left(\frac{a^{2} \Omega p}{4(1+r)}\right)^{\frac{2}{3}}
$$


Notice that the investment of the outsider is positively related to the chance that he can outperform his rival. We can draw figure 1 that illustrates the supply and demand functions for human capital dependent on bonus demand if we choose the parameters below:

$$
r=0.05, a^{2}=0.25, p=5, \Omega_{1}=0.25, \Omega_{2}=0.5, \Omega_{3}=0.75
$$

The graph depicts equations (4.4) and (4.5) with bonus w on the ordinate dependent on the level of newly acquired human capital $c$ on the abscissa. The decreasing hyperbola depicts the demand function of the firm, while the increasing lines are the supply functions of the potential entrant dependent on $\Omega$. At the steepest line the chance of the outsider to outperform the insider is 0.25 , inbetween $\Omega=0.5$ and at the flattest line the chance is 0.75 . The higher the chance to outperform the rival, the

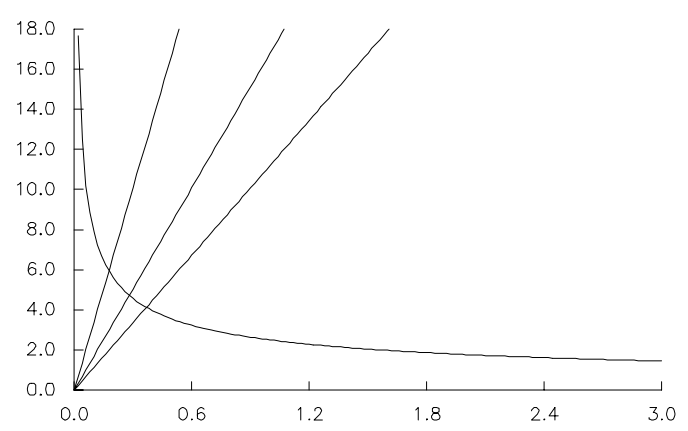

Figure 1 lower the bonus demand of the potential entrant for a given level of investment.

The equilibrium bonus demand of the potential entrant is then derived by substituting (4.6) into (4.5) or (4.4):

$$
W^{e}=\left(\frac{(1+r) p^{2}}{2 \Omega a^{2}}\right)^{\frac{1}{3}}
$$

The bonus demand of the outsider is negatively related to the chance to outperform the incumbent $\Omega$. From bonus demand and investment of the potential entrant, the expected profit and the profit in both realizations of the stochast can be derived by substituting (4.6) and (4.7) into (2.2), (2.3) and (2.4) respectively:

$$
\mathrm{E} \pi^{\mathrm{e}}=\mathrm{px}^{\frac{1}{2}}-\mathrm{vx}+\frac{1}{2} \Omega^{\frac{1}{3}} \alpha
$$




$$
\begin{aligned}
& \pi_{\text {low }}^{\mathrm{e}}=\mathrm{px}^{\frac{1}{2}}-\mathrm{vx}+\left(\frac{1}{2}-\epsilon\right) \Omega^{\frac{1}{3}} \alpha \\
& \pi_{\text {high }}^{\mathrm{e}}=\mathrm{px}^{\frac{1}{2}}-\mathrm{vx}+\left(\frac{1}{2}+\epsilon\right) \Omega^{\frac{1}{3}} \alpha
\end{aligned}
$$

As $\varepsilon$ is assumed to be smaller than 0.25 , the firm is not worse off in the bad case with innovation than without innovation in human capital and the profit is above the reservation level. Notice that the profit of the firm is positively related to the probability that the potential entrant can outperform the incumbent $\Omega$, or stated differently, the potential entrant confronted with a low chance to outperform the insider reduces investment in human capital and increases bonus demand and offers the firm consequently a smaller profit.

\subsection{The Behaviour of the Incumbent}

The incumbent knows the structure of chances and the reaction of the outsider on certain chances to outperform her. As she has the first-mover advantage, she will set a commitment in investment in human captital that gives her the highest expected surplus taking the reaction of the rival into account. Therefore the incumbent has indirectly the possibility to determine $\Omega$ by commiting herself in the first stage. If the potential entrant sees no chance to outperform the insider $(\Omega=0)$, we call that preemptive behaviour, while positive values of $\Omega$ are called accomodation. The expected surplus of the incumbent is derived analogously from (4.1):

$$
\operatorname{ES}\left(i^{i}, W^{i}\right):=[1-\Omega]\left(v x+w^{i} c^{i}-(1+r) i^{i}\right)+\Omega\left(u-(1+r) i^{i}\right)
$$

The highest profit of the incumbent -i.e. the monopolist profit- is reached, if she can credibly preempt the entrant from challenging her position and investing the amount in human capital, she would have invested being a monopolist (3.10). In the fourth stage because the potential entrant did not invest at all $(\Omega=0)$ - she is then able to charge the monopolistic bonus (3.11). This is a possible Nash-equilibrium.

If the incumbent has invested and the preemption threat is not credible, because 
the surplus with accomodation is higher for the incumbent, the outsider has an incentive to invest himself and challenge the incumbent. There are three possible scenarios ${ }^{14}$ where the potential entrant has a positive chance to outperform the incumbent and in comparing the surplus the incumbent enjoys with preemption in comparison to the surplus attached to accomodation, we can tell if premption is credible.

The first step is now to derive the optimal surplus the incumbent enjoys when she preempts and the surplus if she accomodates and check, if preemption is advantageous for her or not.

In order to preempt, the incumbent has to charge a bonus such that (compare table 2):

$$
\pi_{\text {low }}^{\mathrm{i}}=\pi_{\text {high }}^{\mathrm{e}}
$$

This constraint on surplus maximizing can be written, by substituting equation (4.10) for $\pi_{\text {high }}^{\mathrm{e}}$ :

$$
\left(\frac{1}{2}+\epsilon\right) \Omega^{\frac{1}{3}} \alpha=(1-\epsilon) \mathrm{pc}^{\frac{1}{2}}-\mathrm{wc}
$$

From this, we can derive the preemptive bonus demand dependent on investment:

$$
\mathrm{W}=\frac{\left(\frac{1}{2}+\epsilon\right) \Omega^{\frac{1}{3}} \alpha}{\mathrm{c}}+(1-\epsilon) \mathrm{pc}^{-\frac{1}{2}}
$$

If expression (4.13) is substituted into the surplus function of the incumbent, in this case the first line of (4.1), because $\Omega=0$ with preemption, the first order derivative of the surplus function with respect to human capital c gives the same increase in human capital as in the monopolistic worker scenario:

$$
c^{\text {pre }}=\left(\frac{a^{2}(1-\epsilon) p}{4(1+r)}\right)^{\frac{2}{3}}=c^{m}
$$

\footnotetext{
${ }^{14}$ We can concentrate on these three cases, because we look for Nash-equilibria. As a posteriori only the three values for $\Omega$ are possible, we can also assume that a-priori and check, if a Nash-equilibrium is reached onder the parameter constellation and the reaction structure of the potential entrant.
} 
The preemptive bonus demand of the incumbent can increase if the commitment of the outsider is lower (or $\Omega$ is smaller). Notice that this investment is not dependent on the a-priori estimation of $\Omega$ by the outsider. If we substitute the investment of the insider (4.14) in the wage function (4.13), we get the preemptive bonus demand:

$$
\mathrm{w}^{\mathrm{pre}}=\frac{(1-\epsilon)-\Omega^{\frac{1}{3}}\left(\frac{1}{2}+\epsilon\right)}{\alpha(1-\epsilon)^{\frac{2}{3}}}
$$

Notice that this constellation with preemption threat on the one hand and investment in human capital by the outsider on the other hand is not a Nash-equilibrium. We need it just in order to check, if the preemption threat of the incumbent is credible (i.e the surplus attached to preemption is higher than the surplus attached to accomodation given the investment of the outsider in the second period).

The (certain) surplus of the incumbent with preemption is then dependent of the commitment of the outsider:

$$
\mathrm{s}^{\mathrm{pre}}=\mathrm{vx}+\left(\frac{3}{4}(1-\epsilon)^{\frac{4}{3}}-\Omega^{\frac{1}{3}}\left(\frac{1}{2}+\epsilon\right)\right) \alpha
$$

This is the optimal surplus of the incumbent when accomodating, dependent on $\Omega$. This surplus has to be compared now with the surplus enjoyed by the incumbent, if he allows for entry of the outsider. If $\Omega$ is 0.25 , the constraint on surplus maximization reads as (compare table 2):

$$
\pi_{\text {low }}^{\mathrm{i}}=\pi_{\text {low }}^{\mathrm{e}}
$$

The analogous calculations for the bonus demand and investment in human capital give the following results:

$$
c^{\text {acc }}=\left(\frac{a^{2}(1-\epsilon) p}{4(1+r)}\right)^{\frac{2}{3}}=c^{m}
$$




$$
\mathrm{w}^{\mathrm{acc}}=\frac{(1-\epsilon)-\left(\frac{1}{4}\right)^{\frac{1}{3}}\left(\frac{1}{2}-\epsilon\right)}{\alpha(1-\epsilon)^{\frac{2}{3}}}
$$

(The superfix "acc" stands for accomodation.) The expected surplus of the incumbent is with accomodation and "offering" the outsider a chance of 0.25 to enter accordingly:

$$
\mathrm{S}^{\mathrm{acc}}=\frac{3}{4} \mathrm{vx}+\frac{1}{4} \mathrm{u}+\frac{3}{4}\left(\frac{2}{3}(1-\epsilon)^{\frac{4}{3}}-\left(\frac{1}{4}\right)^{\frac{1}{3}}\left(\frac{1}{2}-\epsilon\right)\right) \alpha
$$

If we substract now (4.16), where $\Omega$ is set 0.25 from (4.19), we get the expression that tells us, if preemption is credible, we strived for:

$$
\mathrm{s}^{\mathrm{acc}}-\mathrm{s}^{\mathrm{pre}}=\frac{1}{4}(\mathrm{u}-\mathrm{vx})+\frac{1}{4}\left(-(1-\epsilon)^{\frac{4}{3}}+\left(\frac{1}{4}\right)^{\frac{1}{3}}\left(\frac{1}{2}+7 \epsilon\right)\right) \alpha
$$

Expression (4.20) is negative -i.e. preemption is credible or $\mathrm{s}^{\mathrm{pre}}>\mathrm{s}^{\mathrm{acc}}-$ if the stochastic parameter $\boldsymbol{\varepsilon}$ is "small" and/or the difference in the wage level between the primary and secondary labour market ( $v x-u$ ) is "large". This is intuitive, because the higher the risk, the higher the mark-up necessary to reach preemption. If $\varepsilon=0$, then a minimal reduction in w leads to preemption. The higher $\varepsilon$ is however, the larger are the overlapping areas between high and low profits of both agents. The larger (vx - u), the higher is the incentive for the incumbent to stay in the primary labour market due to the wage loss if she is outperformed by her rival. The results for the scenarios with $\Omega=0.5$ and $\Omega$ $=0.75$ are given for completeness in the appendix .

Now we can determine the strategy of the potential entrant: It is shown in the appendix, that the higher the commitment of the outsider the smaller is the chance that accomodation is advantageous for the insider. Consequently he should never commit himself that strongly, because the incumbent will always set a bonus that gives him no chance to outperform his rival. Then the sunk investment costs can not be earned back and he would end up with a surplus smaller than u. If (4.20) is positive, then the outsider 
should invest according to (4.4) with $\Omega=0.25$, because it is advantageous for the incumbent to accomodate. If however even (4.20) is negative, i.e. there is a considerable uncertainty concerning the effectivenes of new human capital and/or there is a large difference between the wage levels in both labour markets, then it is efficient for the potential entrant not to invest at all and stay in the secondary labour market. The incumbent can then consequently charge the monopoly bonus (3.11) and gets the highest possible share on the social surplus.

If the threat is not credible with the incumbent's monopolistic investment (3.10), i.e. (4.20) is positive, it is probably better for the incumbent to reduce her commitment in stage 1 in order to achieve a credible threat of preemption. The certain monopolist bonus in connection with this reduced investment gives probably a higher surplus than the higher investment with the risk that the sunk costs are lost. As the requirements on the exogeneous parameters $\varepsilon$ and ( $v x-u)$ decrease with the commitment of the incumbent in the first stage, a reduced investment can lead to a credible threat even if (4.20) is positive.

The "critical" investment is derived by equalizing the surplus enjoyed by the incumbent in the cooperative and preemptive scenario:

$$
\mathrm{s}^{\mathrm{pre}}=\mathrm{vx}+\mathrm{w}^{\mathrm{pre}} \mathrm{c}=3 / 4 \mathrm{vx}+1 / 4 \mathrm{u}+3 / 4 \mathrm{w}^{\mathrm{pre}} \mathrm{c}=\mathrm{s}^{\mathrm{acc}}
$$

Here $\mathrm{w}^{\mathrm{pre}}$ is taken from (4.13) and $\mathrm{w}^{\mathrm{acc}}$ is derived analogously. If we call the threshold increase in human capital z, we get the following expression for it:

$$
z=\left[\frac{(u-v x)+4^{\frac{2}{3}} \alpha\left(\frac{1}{2}+\epsilon\right)+\left(\frac{27}{4}\right)^{\frac{1}{3}} \alpha\left(\frac{1}{2}-\epsilon\right)}{(1-\epsilon) p}\right]^{2}
$$

Comparative statics of the critical investment reveal the proper signs:

$$
\begin{gathered}
\frac{\partial z}{\partial \epsilon}>0 \\
\frac{\partial z}{\partial(v x-u)}<0
\end{gathered}
$$


Notice that $\mathrm{z}$ is always larger than zero, except $\varepsilon=1 / 7$ or $(u-v x)$ is exactly equal to the right part of the numerator. The upper bound of $\mathrm{z}$ is of course the monopolistic investment in human capital (3.10), because then the social surplus that can be distributed between insider and firm is maximal. Higher investment would decrease the chance of the incumbent to outperform the potential entrant. If uncertainty increases, the preemption threat gets more credible, i.e. the commitment of the incumbent can be high and maximally on the monopolistic level. If the difference between the wage levels increases however, the commitment of the incumbent should decrease however in order to threaten credibly and therefore depart further from dynamic efficiency.

The last step for the incumbent is to compare the surplus gained by the credible preemption threat and investment z with the surplus enjoyed if she invested (3.10) and accomodated afterwards with $\Omega=0.25$. In order to derive the surplus with preemption, the "monopolistic" bonus has to be calculated that gives the firm her reservation profit in the bad state of nature $\left(\pi_{\text {low }}^{\mathrm{i}}(\mathrm{z})=\mathrm{px}^{\mathrm{k}}-\mathrm{vx}\right)$, i.e. (3.8) with $\mathrm{z}$ substituted for $\mathrm{c}^{\mathrm{m}}$. The expression for $\mathrm{w}^{\mathrm{i}}$ is then substituted into the surplus function of the incumbent (2.4) and we get:

$$
S^{\mathrm{pre}}=\mathrm{VX}+(1-\varepsilon) \mathrm{pz}^{\mathrm{h}}-\frac{(1+\mathbf{r}) \mathbf{z}^{2}}{\mathbf{a}^{2}}
$$

This surplus has to be compared with (4.19), the surplus enjoyed with accomodation. The Nash-equilibrium is then: Preemption with investment $\mathrm{z}$, if (4.24) > (4.19) and accomodation with investment (3.10) otherwise.

It can be shown that $s^{\text {pre }}$ is for all parameter constellations larger than $s^{\text {acc }} .15$ Therefore even if $\boldsymbol{\varepsilon}=0.25$ and $(\mathrm{vx}-\mathrm{u})=0$, it is advantageous for the incumbent to keep the outsider off the primary labour market. The same reasoning applies for the other scenarios with higher commitments of the outsider shown in the appendix. As we want to show just the quantitative results here, it is therefore not necessary to compute the relation between the surplusses of the incumbent. If the difference between the wage levels in both labour markets is however very small and the uncertainty high, such that

\footnotetext{
${ }^{15}$ Intuition: a low investment $\mathrm{z}$ is just reached, if $(\mathrm{vx}-\mathrm{u})$ is large and $\varepsilon$ is small. In this case $\mathrm{s}^{\mathrm{pre}}$ is just a little larger than vx. The surplus with accomodation $\mathrm{s}^{\mathrm{acc}}$ is in this case however smaller than vx (compare (4.19)).
} 
even with a high commitment of the outsider the threat to preempt is not credible, the insider will choose the appropriate z-level given in the appendix.

Expected social welfare is with preemption and investment z:

$$
\mathrm{ESW}=\mathrm{p}\left(\mathrm{x}^{\mathrm{k}}+\mathrm{Z}^{\mathrm{k}}\right)-\mathrm{vX}-\mathrm{W}^{\mathrm{m}} \mathrm{Z}=\mathrm{E} \pi
$$

This is clearly smaller than in the preemptive scenario with "monopolistic" investment, because social surplus is not maximal and the slice of the social welfare the firm enjoys is still the premium on reservation profit the incumbent forcedly has to concede in the good state of nature.

\section{Results}

The results of the different scenarios in the present model can be summarized in the table below:

\begin{tabular}{|c|c|c|c|c|c|}
\hline & social planner & $\begin{array}{l}\text { monopolistic } \\
\text { worker }\end{array}$ & $\begin{array}{l}\text { monopso- } \\
\text { nistic firm }\end{array}$ & $\begin{array}{l}\text { preemption } \\
\text { with } c^{\text {mon }}\end{array}$ & $\begin{array}{l}\text { preemption } \\
\text { with } \mathrm{z}\end{array}$ \\
\hline c & $\sqrt{ } \alpha$ & $(1-\varepsilon)^{2 / 3} c^{s p}$ & $0.63 c^{\mathrm{sp}}$ & $(1-\varepsilon)^{2 / 3} c^{s p}$ & $\mathrm{Z}$ \\
\hline W & $\left(\frac{(1+r) p^{2}}{16 a^{2}}\right)^{\frac{1}{3}}$ & $4(1-\boldsymbol{\varepsilon})^{2 / 3} \mathrm{~W}^{\mathrm{sp}}$ & $\approx 0.6 \mathrm{~W}^{\mathrm{sp}}$ & $4(1-\boldsymbol{\varepsilon})^{2 / 3} W^{\mathrm{sp}}$ & $\frac{(1-\epsilon) \mathbf{p}}{\sqrt{\mathbf{z}}}$ \\
\hline $\begin{array}{l}E(\pi)- \\
\pi^{\min }\end{array}$ & $3 / 4 \alpha$ & $\begin{array}{l}(1-\varepsilon)^{-} \\
{ }^{1 / 3} 4 / 3 \boldsymbol{\varepsilon} \pi^{\mathrm{sp}}\end{array}$ & $\approx 0.6 \pi^{\mathrm{sp}}$ & $(1-\varepsilon)^{1 / 3} \varepsilon \alpha$ & $\begin{array}{l}\mathrm{p} \mathrm{V}_{\mathrm{Z}^{-}} \\
(1-\boldsymbol{\varepsilon}) \mathrm{p} \sqrt{\mathrm{Z}}\end{array}$ \\
\hline $\begin{array}{l}E(S)- \\
v X\end{array}$ & 0 & $\begin{aligned} & \frac{3}{4}(1-\epsilon)^{\frac{4}{3}} \alpha \\
= & {[0.51,0.75] \alpha }\end{aligned}$ & $\approx 0.1 \alpha$ & $\begin{aligned} & \frac{3}{4}(1-\epsilon)^{\frac{4}{3}} \alpha \\
= & {[0.51,0.75] \alpha }\end{aligned}$ & $\begin{array}{l}(1-\varepsilon) p \sqrt{ } z- \\
(1+r) z^{2} / a^{2}\end{array}$ \\
\hline
\end{tabular}

If we consider the results of the bench-mark scenarios in the third chapter, we can conclude that the monopolistic worker has an incentive to invest dynamically efficiently in human capital if there is no uncertainty concerning the usability of the newly acquired 
human capital, because she has then the opportunity to acquire almost the entire social surplus created by the additional human capital. Due to the possibility to skim most of the rent, the monopolistic worker scenario is statically highly inefficient. The larger the stochast gets however, the larger is the share of the social surplus the monopolist has to grant the firm due to the reservation profit vx that must not be undercut in the bad realization of the stochast. The difference between the profit in the good case and the reservation profit offered in the bad case is therefore the share on the social surplus the monopolist has to let the firm. The larger the part of the social surplus the monopolist has to grant the firm the lower the incentive to invest efficiently. Consequently, the investment in human capital falls with uncertainty. Social welfare increases however with the stochast, because bonus demanded decreases "faster" than investment in human capital.

In the benchmark with a wage-setting firm, the investment in human capital is inefficiently low, because the worker is not able to acquire large a share of the social surplus due to the low granted bonus. This produces a trade-off between static and dynamic efficiency, if we compare this scenario with the monopolistic worker scenario. Due to the small incentive to invest the wage-taking worker scenario performs bad on dynamic efficieny, while the impact of the firm on bonus setting secures a high level of static efficiency. Taken together, the monopolistic firm scenario performs unambigously worse than the scenario where the firm sets the bonus.

According to the notion of Stiglitz, "when there is strong ex post competition even small sunk costs act as effective entry barriers" ${ }^{\prime \prime 16}$, we get the result that with all parameter constellations, it is optimal for the incumbent to preempt her rival from entering the primary labour market. In our case, not entry itself causes sunk costs, but investment in human capital and ex-post competition is completely effective (the former incumbent has no chance to win his position back). In addition to that, exit is not costless, because sunk costs for the investment in human capital are lost for the incumbent and the wage level in the secondary labour market is lower than that in the primary labour market. Another assumption that drives the results of this model is the minimal advantage the incumbent enjoys if the profits offered to the firm in the primary

\footnotetext{
${ }^{16}$ See Stiglitz (1987), pp. 889f.
} 
labour market are equal and the first-mover advantage of the insider. This worsens the chance-distribution for the outsider considerably and therefore his incentive to sink costs.

In the insider-outsider scenario we have to check, if the threat of preemption is credible or if the insider would accomodate if the outsider makes a commitment. On the one hand the threat to preempt gets the more credible the smaller the uncertainty about the effectiveness of the investment (or the lower the premium on the bonus in the negative state of nature necessary to preempt). On the other hand the higher the "punishment" with loosing the job for the incumbent (or the lower the difference between the wage levels in both labour markets), the more credible is the threat of preemption. It is shown that it is always better for the incumbent to reduce her commitment if the parameter constellation is such that the preemption threat is not credible in order to get a credible threat than investing surplus maximizing and allowing hereby for entry.

The surplus maximizing investment is with preemption the monopolistic investment. This is also the case, if the commitment of the outsider was small $(\Omega=0.25)$. The surplus of the incumbent would be maximized with an investment that is larger than dynamically efficient, if the potential entrant had a higher commitment and the insider found it advantageous to accomodate (this is scenario is irrelevant.)

Taken together, we get two possible results. The first one is that the incumbent invests like a monopolist and preempts. Then she can charge also the monopolistic bonus and the welfare result is the same as in the scenario with a monopolistic worker with static inefficiency and almost dynamic efficiency if there is small uncertainty. Secondly, there is the possibility that the incumbent credibly preempts with a smaller investment $\mathrm{z}$ and charges the monopolistic bonus in stage 4. Here potential entry distorts the investment decision of the incumbent worker. In this case the social welfare is smaller than in the first scenario, because the investment of the incumbent is now even lower than in the first case, but the worker enjoys still the lion's share of the rent due to the monopolistic bonus setting that gives the firm just a small part of the (reduced) social surplus. In this case therefore, neither dynamical nor statical efficiency is reached.

\section{Appendix}


In the second scenario in which the potential entrant commits himself such that his a-posteriori chance $\Omega=0.5$ is consistent, we have to substitute $\Omega=0.5$ into (4.16) in order to obtain the surplus with preemption:

$$
\mathrm{s}^{\mathrm{pre}}=\mathrm{vx}+\left(\frac{3}{4}(1-\epsilon)^{\frac{4}{3}}-\left(\frac{1}{2}\right)^{\frac{1}{3}}\left(\frac{1}{2}+\epsilon\right)\right) \alpha
$$

Notice that the surplus earned with preemption is lower in the scenario with $\Omega=0.5$ than with $\Omega=0.25$. This is obvious, because the profit the outsider offers in the first scenario in the positive realization of the stochast is lower than that with $\Omega=0.5$. Therefore the incumbent has to share a larger part of the rent generated by the newly acquired human capital with the firm in order to keep the entrant out of the game.

The expected surplus of the incumbent with accomodation is calculated by substituting $\Omega=0.5$ into (4.10) again and calculating the optimal investment under the constraint (see table 2)

$$
\pi_{\text {high }}^{\mathrm{i}}=\pi_{\text {high }}^{\mathrm{e}}
$$

analogously to the procedure above:

$$
\mathrm{c}^{\mathrm{acc}}=\left(\frac{\mathrm{a}^{2}(1+\epsilon) \mathrm{p}}{4(1+\mathrm{r})}\right)^{\frac{2}{3}}
$$

Notice that the surplus-maximizing investment in human capital of the insider is larger than dynamically efficient if there is uncertainty and larger than the monopolistic investment.

$$
\mathrm{s}^{\mathrm{acc}}=\frac{1}{2}(\mathrm{vx}+\mathrm{u})+\left(\frac{1}{4}(1+\epsilon)^{\frac{4}{3}}-\left(\frac{1}{2}\right)^{\frac{4}{3}}\left(\frac{1}{2}+\epsilon\right)\right) \alpha
$$

If we substract $\mathrm{s}^{\text {acc }}$ from $\mathrm{s}^{\text {pre }}$, we get analogously to (4.20) the expression:

$$
\mathrm{s}^{\mathrm{acc}}-\mathrm{s}^{\mathrm{pre}}=\frac{1}{2}(\mathrm{u}-\mathrm{vx})+\left(\frac{1}{4}(1+\epsilon)^{\frac{4}{3}}-\frac{3}{4}(1-\epsilon)^{\frac{4}{3}}+\left(\frac{1}{2}\right)^{\frac{4}{3}}\left(\frac{1}{2}+\epsilon\right)\right) \alpha
$$


The analogous $\mathrm{z}$-level that grants a credible preemption threat if (A1) is positive reads then as:

$$
z=\left[\frac{(u-v x)-\left(\frac{1}{2}+\epsilon\right)\left(\frac{1}{2}\right)^{\frac{1}{3}} \alpha}{(1+\epsilon) p}\right]^{2}
$$

In the third scenario with $\Omega=0.75$, we get the analogous difference between both surpluses:

$$
\begin{gathered}
\mathrm{s}^{\mathrm{acc}-\mathrm{s}^{\mathrm{pre}}}=\frac{3}{4}(\mathrm{u}-\mathrm{vx})+\left(\frac{1}{2}(1+\epsilon)^{\frac{4}{3}}-\frac{3}{4}(1-\epsilon)^{\frac{4}{3}}\right) \alpha \\
+\left(\left(\frac{3}{4}\right)^{\frac{1}{3}}\left(\frac{1}{2}+\epsilon\right)-\left(\frac{1}{2}\right)\left(\frac{3}{4}\right)^{\frac{1}{3}}\left(\frac{1}{2}-\epsilon\right)\right) \alpha
\end{gathered}
$$

Notice that the "requirement", the parameter $\boldsymbol{\varepsilon}$ has to fulfill to reach a credible threat, increases with $\Omega$. On the other hand the negative impact of $(u-v x)$ increases on the result with $\Omega$. Taken together, the higher the commitment of the potential entrant the higher the a-priori chance of the incumbent that the parameter constellation leads to an credible commitment.

\section{Literature}

William S. Baumol, John C. Panzar, Robert C. Willig: "Contestable Markets and the Theory of Industry Structure", San Diego: Harcourt Brace Jovanovich, 1988 Gary S. Becker: "Human Capital", Chicago: University of Chicago Press, 2nd edition, (Midway reprint), 1983

Robert Hart: "The Economics of Non-wage Labour Costs", London: Allen and Unwin, 1984

Assar Lindbeck, Dennis J. Snower: The Insider-Outsider Theory of Employment and Unemployment, Cambridge, Mass.: The MIT Press, 1988 
Marius Schwartz: "The nature and Scope of Contestability Theory", in: "Strategic Behaviour and Industrial Competition", ed. by D. J. Morris et al., Oxford: Clarendon Press, 1986

William G. Shepherd: "Contestability" vs. Competition", American Economic Review, 74, No. 4, pp. 572 - 587, 1984 Joseph Stiglitz: "Technological Change, Sunk Costs and Competition", Brookings Papers on Economic Activity, 3, pp. 883-937, 1987 Jean Tirole: "The Theory of Industrial Organization", Cambridge, Mass.: The MIT Press, 1988

A. van Witteloostuijn: "Statische en dynamische efficiëntie op de arbeidsmarkt: potentiële concurrentie en marktprestaties, Maandschrift Economie, 53, pp. 278 $-291,1989$

A. van Witteloostuijn: "Rationality, competition and evolution - Entry (deterrence) in dynamic barrier market theory", Maastricht, 1990 